\title{
Correction to: Multiple Emulsions for Enhanced Delivery of Vitamins and Iron Micronutrients and Their Application for Food Fortification
}

\author{
Shima Saffarionpour ${ }^{1} \cdot$ Levente L. Diosady ${ }^{2}$
}

Published online: 9 July 2021

๑) Springer Science+Business Media, LLC, part of Springer Nature 2021

Correction to: Food and Bioprocess Technology (2021) 14:587-625 https://doi.org/10.1007/s1 1947-021-02586-2

The original version of this article unfortunately contained some mistakes. In the published version of our article, Tables 1 and 2 are not published completely and only the first page of the tables is included in the article.

With this, here are the complete Tables 1 and 2.

The original article can be found online at https://doi.org/10.1007/ s11947-021-02586-2.

Shima Saffarionpour

ssaffarion@gmail.com

1 Montreal, Québec, Canada

2 Department of Chemical Engineering and Applied Chemistry, University of Toronto, Toronto, Canada 
1612

Food and Bioprocess Technology (2021) 14:1611-1614

Table 1 Molecular structure and physical properties of vitamins (ChemAxon 2020; DrugBank 2020; Peinado et al. 2019)

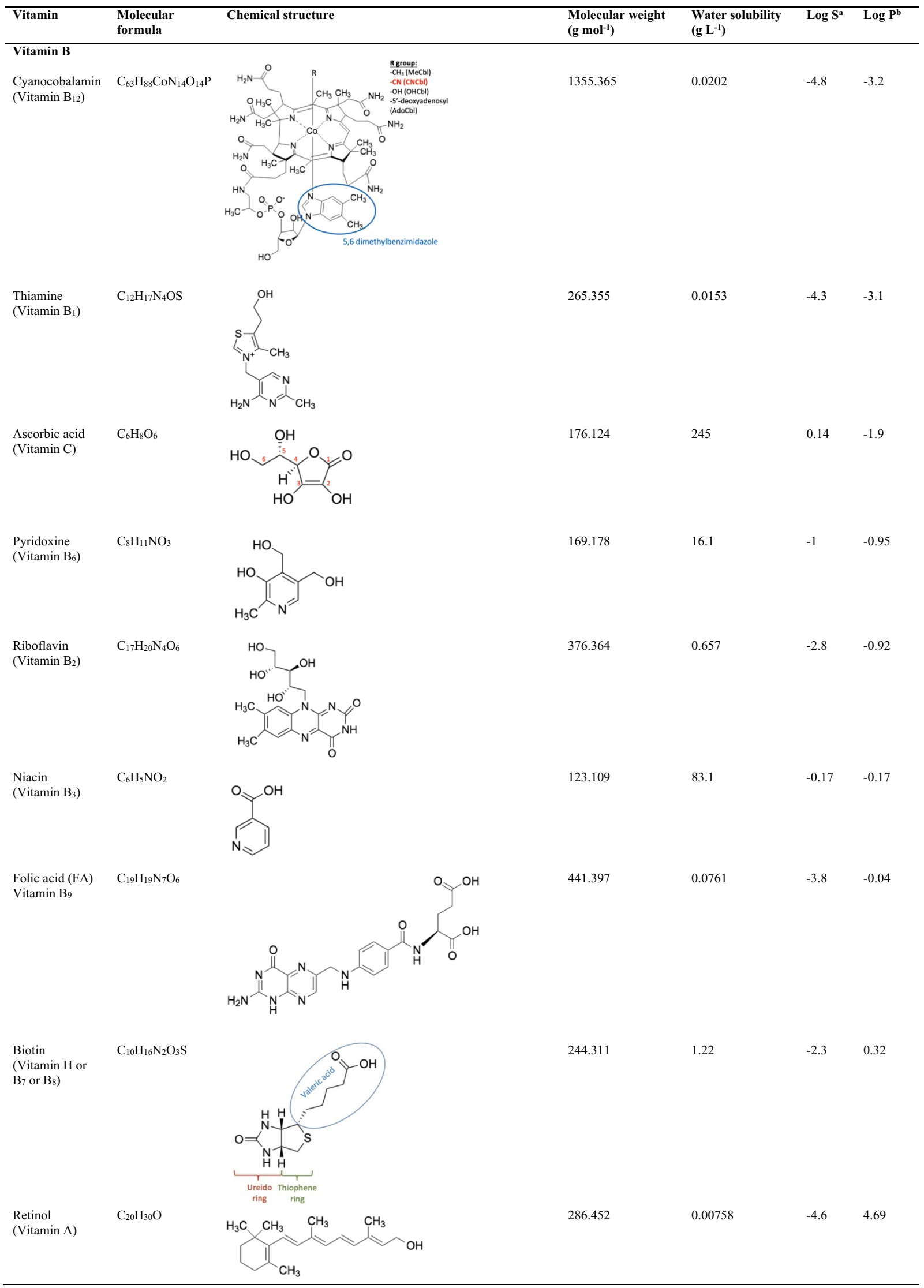

Springer 
Table 1 (continued)

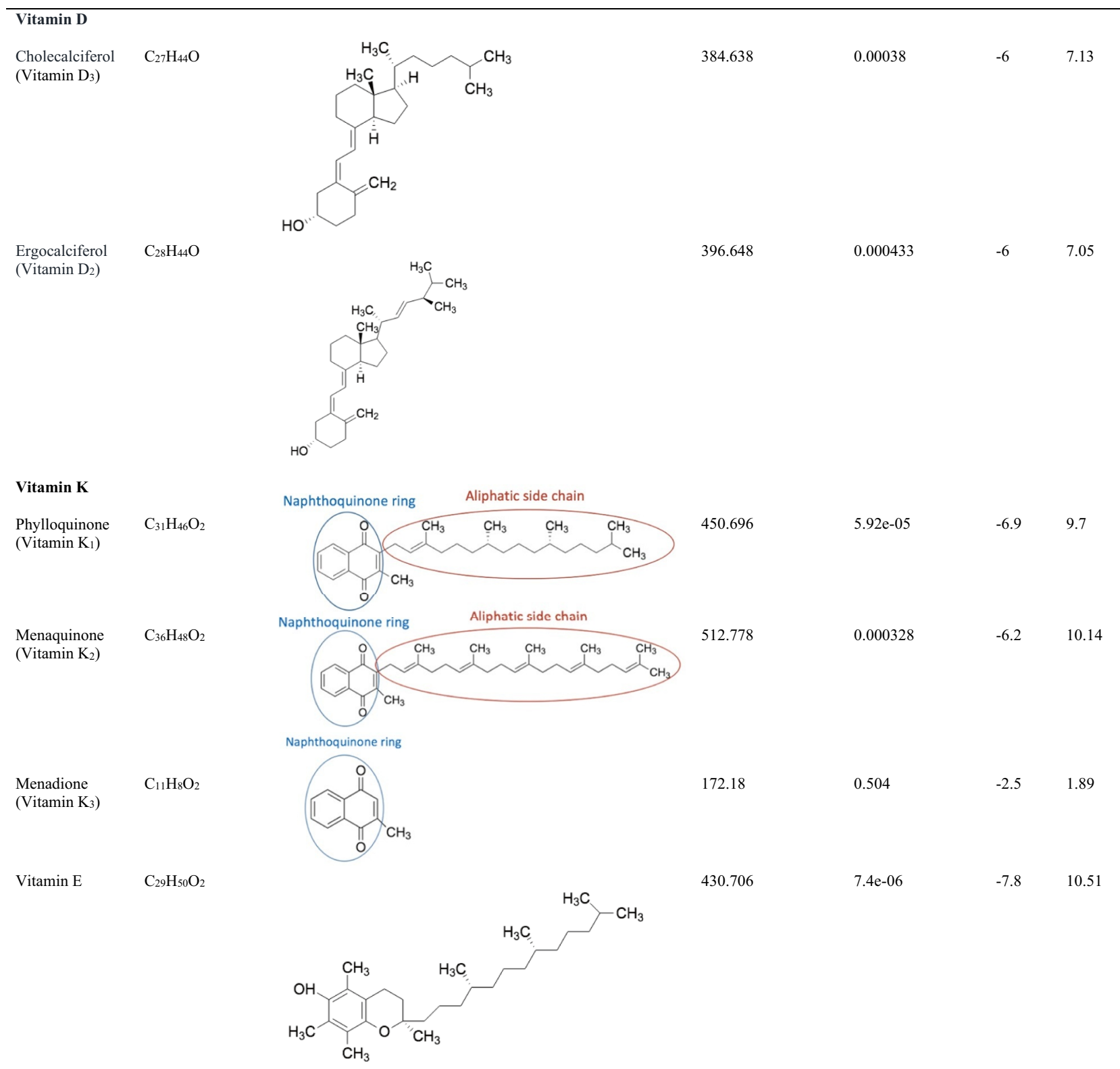

${ }^{\mathrm{a}} \log \mathrm{S}$ is the 10-base logarithmic measurement of solubility

${ }^{\mathrm{b}} \log \mathrm{P}$ is the 10 -base logarithmic measurement of the partition coefficient in octanol-water solution 
Table 2 Molecular structure and physical properties of iron (ChemAxon 2020; DrugBank 2020)

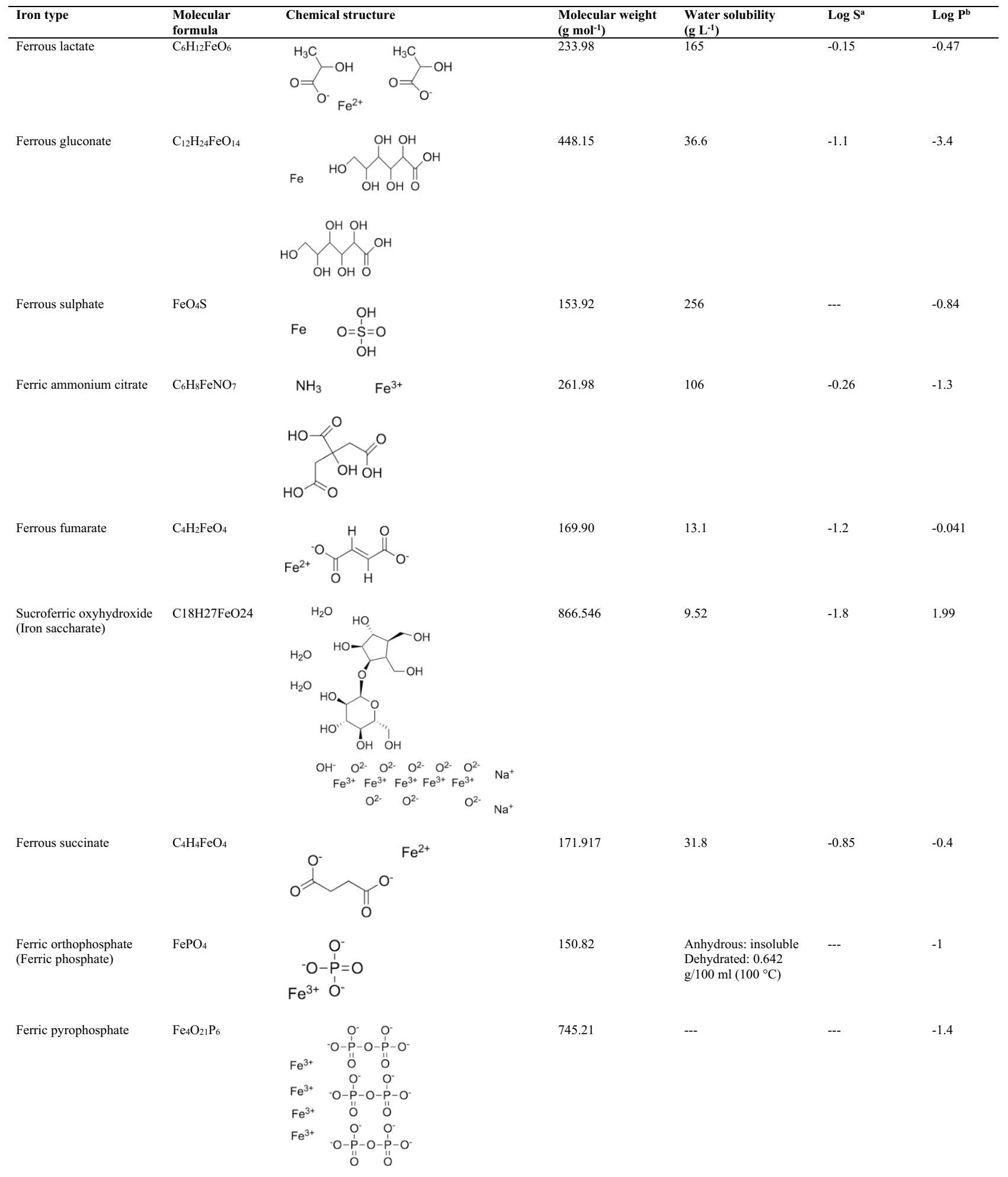

